\title{
CSN6 and Rab34 Are Involved in Androgen Receptor Trafficking in Mouse Testicular Sertoli Cells
}

\author{
Qiong Deng ${ }^{\mathrm{a}} \quad$ Chihua $_{\mathrm{He}}^{\mathrm{b}} \quad$ Yong Wu $^{\mathrm{b}} \quad$ Jianwen Zhang ${ }^{\mathrm{a}} \quad$ Ying Zhang $^{\mathrm{a}}$ \\ Zhu Wang $^{\text {a Hui Liang }}{ }^{\text {a Fei Yang }}{ }^{c}$ \\ aDepartment of Urology, The People's Hospital of Longhua, Shenzhen, bReproductive Center, Jingzhou \\ Central Hospital, The Second Clinical Medical College, Yangtze University, Jingzhou, 'Department of \\ Urology, The Third Affiliated Hospital of Sun Yat-Sen University, Guangzhou, China
}

\section{Key Words}

Androgen receptor • Sertoli cells $•$ CSN6 $・$ Rab34 • Phosphorylation signaling pathway

\begin{abstract}
Background/Aims: Androgen and its receptor (AR) play an important role in maintaining spermatogenesis and male fertility. Our previous studies showed that testosterone at a physiological concentration induces cytoplasmic AR translocation to the Sertoli cell plasma membrane of within 5 minutes. Methods: In this study, mass spectrometry (MS) and bioinformatic analyses were applied to identify candidate proteins mediating AR trafficking. The candidate proteins were knocked down by shRNA transfection. Results: Nine candidate proteins were identified by MS. The data was verified by co-immunoprecipitation and Western blot. Of the candidates, CSN6 regulated AR transport through the phosphorylation signaling pathway and Rab34 affected AR trafficking by regulating Ras activity. Conclusions: CSN6 and Rab34 are involved in AR trafficking by regulating the phosphorylation signaling pathway. These findings provide new insights into the testosterone signaling pathway in Sertoli cells that mediates spermatogenesis.
\end{abstract}

\section{Introduction}

Androgen and its receptor (AR) play an important role in maintaining spermatogenesis and male fertility. The actions of androgen in Sertoli cells are essential for spermatogenesis. In mice with $A R$ knockout Sertoli cells, spermatogenesis is arrested predominantly at the diplotene primary spermatocyte stage before the accomplishment of first meiotic division [1-3], similar to the phenotype of $A R$ knockout mice. The selected $A R$ knockout in germ cells does not affect spermatogenesis [4]. These data suggested that the AR in Sertoli cells of seminiferous tubules is critical for spermatogenesis.

Q.Deng and C. He contributed equally to this work.

Hui Liang

and Fei Yang

KARGER
Department of Urology, The People's Hospital of Longhua

No. 2, Jianshedong Road, Longhua District, Shenzhen, 518109 (China)

Tel. +86 7552774 1585-8689, E-Mail lianghui1976@163.com yangfei30@163.com 


\section{Cellular Physiology Cell Physiol Biochem 2018;47:2360-2368

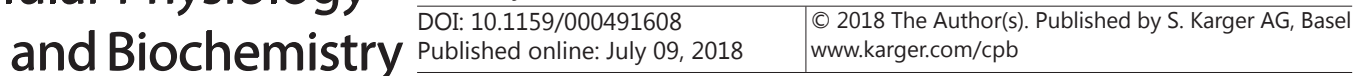 Deng et al.: CSN6 and Rab34 in AR Trafficking}

AR associates with charpone proteins, including Heat Shock Protein 70/90, immunophilins and other molecular factors in the cytoplasm, and forms a stable complex. Testosterone is the main androgen in the testis. It is secreted by Leydig cells, diffuses into the cytoplasm, binds with AR and induces the dissociation of AR from the complex. The ARtestosterone complex translocates to the nucleus and binds with the androgen response element (ARE) in the chromatin, which induces gene transcriptional repression or activation. This classical pathway of androgen requires approximately 40 minutes, since it requires the establishment of a productive transcription product [5], as well as new protein synthesis and secretion. A non-classical signaling pathway that is completed in a shorter time (several seconds to minutes) has been identified. It is markedly faster because it does not involve RNA transcription or protein synthesis [6].The fast action is mediated by a membrane associated receptor of androgens.

A hypothesis dating to the early 1980s that non-genomic effects of glucocorticoids are mediated by a membrane receptor [7]. A mechanism was reported that palmitoylation of a cysteine in the conserved region of the estrogen receptor (ER) increases the receptor's membrane association [8]. The progesterone receptor is also reportedly localized in the plasma membrane $[9,10]$. We previously reported that AR is localized to the membrane of murine testicular TM 4 cells by binding to a caveolae protein Caveolin-1, and that testosterone enhanced the membrane association of AR [11]. However, the mechanism mediating cytoplasmic AR trafficking to the membrane remains unclear.

In this study, co-immunoprecipitation (co-IP) and mass spectrometry (MS) were used to identify the candidate proteins involved in AR trafficking and membrane anchoring. Bioinformatics analysis and co-IP combined with immunoblot analysis were used to verify the MS data. The screened candidate proteins were knocked down using short hairpin (sh) RNA constructs to test their roles in AR trafficking. We also studied the molecular mechanism mediating AR trafficking by the candidate protein. This data we present will further clarify the mechanism of action of androgens, and provide new insights into the testosterone signaling pathway in Sertoli cells mediating spermatogenesis.

\section{Materials and Methods}

\section{Reagents and constructs}

Unless other indicated, all the chemical reagents were obtained from Sigma-Aldrich (USA) and all cell culture reagents were bought from Life Technologies (USA). The shRNA constructs were provided by Shanghai Genechem Co., Ltd. (China).

Isolation and primary culture of mouse Sertoli cells

A modified method was used to isolate primary Sertoli cells from the testes of 6-8-week-old wild type C57BL/6 mice [12]. Two cultures of primary Sertoli cells were prepared both using four adult mice on one day. Testes were decapsulated and the seminiferous tubules were pooled and washed three times with phosphate-buffered saline (PBS). The tubules then were incubated with $2 \mathrm{mg} / \mathrm{ml}$ collagenase I and $0.5 \mathrm{mg} /$ $\mathrm{ml}$ Dnase I in Dulbecco's Modified Eagle's Medium (DMEM, Gibco) for $20 \mathrm{~min}$ at $37^{\circ} \mathrm{C}$ on a shaker. The tubules were then washed twice with PBS and further digested with $2 \mathrm{mg} / \mathrm{ml}$ collagenase I, $0.5 \mathrm{mg} / \mathrm{ml}$ Dnase I and $1 \mathrm{mg} / \mathrm{ml}$ hyaluronidase type III for $10 \mathrm{~min}$ at $37^{\circ} \mathrm{C}$ on a shaker. The tubules were allowed to settle and were washed twice with PBS. The tubules were further digested with $2 \mathrm{mg} / \mathrm{ml}$ collagenase I, $0.5 \mathrm{mg} / \mathrm{ml}$ Dnase I, $2 \mathrm{mg} / \mathrm{ml}$ hyaluronidase, and $1 \mathrm{mg} / \mathrm{ml}$ trypsin for $20 \mathrm{~min}$ at $37^{\circ} \mathrm{C}$ on a shaker. Cell culture medium (DMEM $+10 \%(\mathrm{v} / \mathrm{v}$ ) fetal bovine serum, FBS) was added to stop the digestion and the sample was gently pipetted up and down to disperse the cells. The final cell suspension contained primarily Sertoli cells and type A spermatogonia. The dispersed cells were washed twice with DMEM and placed into culture dishes in DMEM containing $10 \%(\mathrm{v} / \mathrm{v}) \mathrm{FBS}$ and incubated at $37^{\circ} \mathrm{C}$ in an atmosphere of $5 \% \mathrm{CO}_{2}$. Spermatogonia were unable to attach to the dish and were removed after the medium was replaced the next day. 


\section{Cellular Physiology Cell Physiol Biochem 2018;47:2360-2368 \begin{tabular}{l|l} 
and Biochemistry Published onlıne: July 09, 2018 & $\begin{array}{l}\text { C) } 2018 \text { The Author(s). Published by S. Karger AG, Basel } \\
\text { www.karger.com/cpb }\end{array}$ \\
\hline
\end{tabular} \\ Deng et al.: CSN6 and Rab34 in AR Trafficking}

\section{Cell culture and transfection}

The TM4 murine Sertoli cell line was purchased from the American Type Culture Collection (USA). Cells were cultured in DMEM (Gibco, Life Technologies) containing 10\% (v/v) FBS, $100 \mu \mathrm{g} / \mathrm{ml}$ penicillin, and 100 $\mu \mathrm{g} / \mathrm{ml}$ streptomycin at $37^{\circ} \mathrm{C}$ in an atmosphere of $5 \% \mathrm{CO}_{2}$. The cells were plated in a 6 -cm cell culture dish (Corning, USA) and were transfected with shRNA or negative control (control shRNA provided by Shanghai Genechem Co., Ltd.; inserted sequence: TTCTCCGAACGTGTCACGT, vector: GV248) using Lipofectamine 3000 (Invitrogen, USA).

\section{Subcellular fractionation isolation and Western blot}

Primary cultured Sertoli cells and TM4 cells plated in 10-cm culture dishes were changed to a medium supplemented with charcoal stripped serum when reaching $80 \%-85 \%$ confluence. Eighteen hours later, the medium was changed to serum-free medium containing $0.1 \%(\mathrm{w} / \mathrm{v})$ bovine serum albumin (BSA) and incubated for $2 \mathrm{~h}$ before exposure to $10 \mathrm{nM}$ testosterone for $30 \mathrm{~min}$ unless otherwise indicated. Cells were harvested and the cytoplasmic, membrane, and nuclear protein fractions were separated using Subcellular Protein Fractionation Kit for Cultured Cells following the instruction of the manufacturer (Pierce, Life Technologies) [13]. Protein concentrations were determined using the bicinchoninic acid protein assay.

Levels of proteins were measured using $20 \mu \mathrm{g}$ of protein or equal volume of co-IP samples. The samples were subjected to SDS-PAGE on 10\% tricine-glycine gels and the resolved proteins were transferred to polyvinyl difluoride membranes (Millipore, USA). After blocking nonspecific protein-binding sites by incubation for $1 \mathrm{~h}$ at room temperature in Tris-buffered saline with $0.2 \%$ Tween 20 (TBST) containing 5\% nonfat dry milk, membranes were incubated overnight with primary antibody ( Table 1). The membranes were washed three times with TBST for 5 min and then incubated with the secondary antibody in 5\% nonfat dry milk at room temperature for $1 \mathrm{~h}$. The specific complexes were detected using the enhanced chemiluminescence system from GE Healthcare (UK). The densitometry of the bands was measured using Image J software (NIH, USA).

\section{Co-IP and MS}

Five hundred microliter aliquots containing 500-1000 $\mu \mathrm{g}$ of protein were subjected to IP using $2.5 \mu \mathrm{g}$ rabbit polyclonal antibody (anti-AR N-20, Santa Cruz Biotechnology, USA; anti-AR, ab74272, Abcam, UK). After separation of immunoprecipitated proteins using magnetic protein A/G Dynabeads (Invitrogen, USA), pellets were washed three times ( 5 min each time) using lysis buffer containing $150 \mathrm{mM} \mathrm{NaCl}, 5 \mathrm{mM} \mathrm{MgCl} \mathrm{z}^{\text {, }}$ $2 \mathrm{mM}$ EGTA, $50 \mathrm{mM}$ Tris- $\mathrm{HCl}$, and $1 \%$ Triton X-100. Proteins were disassociated from the magnetic beads by incubating with $0.1 \mathrm{M}$ glycine $(\mathrm{pH} 2.2-2.7)$ for $10 \mathrm{~min}$. The co-IP samples from $120 \times 10^{6}$ cells were sent to FitGene Biotechnology Co. Ltd. (China) for MS detection. Multi-dimensional protein identification technology was applied for proteins identification and the candidate proteins were subjected to bioinformatic analysis.

\section{Active Ras detection assay}

Ras activity was detected using the Active Ras detection kit from Cell Signaling Technologies (USA, Cat. \#8821). Briefly, cells transfected with negative control or Rab34 shRNAwereharvested.Celllysate was extracted by lysis buffer provided by the kit, and diluted to $1 \mathrm{mg} / \mathrm{ml}$. Five microliters of $10 \mathrm{mM}$ guanosine 5'-0-[gammathio] triphosphate (GTP $\gamma \mathrm{S})$ or $10 \mathrm{mM}$ GDP was added to 500 $\mu \mathrm{g}$ of the cell lysate and the mixture was incubated at $30^{\circ} \mathrm{C}$ for $15 \mathrm{~min}$. After terminating the reaction by adding $\mathrm{MgCl}_{2}$ (final concentration $60 \mathrm{mM}$ ), the cell lysate was added to a spin cup pre-loaded with $80 \mu \mathrm{g}$

Table 1. Antibodies used for Western blot analysis. *SCBT: Santa Cruz Biotechnology; CST\#: Cell Signaling Biotechnology

\begin{tabular}{lcccc}
\hline Antibody & Specie & Catalog & Dilution & Source \\
\hline AR (N-20) & Rabbit & sc-816 & $1: 1000$ & SCBT* \\
Pan Cadherin & Mouse & ab22744 & $1: 5000$ & Abcam \\
GAPDH & Rabbit & $\# 5174$ & $1: 1000$ & CST $^{\#}$ \\
HDAC & Rabbit & ab53091 & $1: 1000$ & Abcam \\
CSN6 & Rabbit & ab77299 & $1: 1000$ & Abcam \\
$\beta$-Actin & Mouse & sc-47778 & $1: 1000$ & SCBT $^{*}$ \\
Phosphor-Akt(Ser473) & Rabbit & $\# 4058$ & $1: 1000$ & CST $^{\#}$ \\
Phospho-Erk1/2(Thr202/Tyr204) & Rabbit & $\# 4370$ & $1: 1000$ & CST $^{\#}$ \\
Phosphor-Mek1/2(Ser217/221) & Rabbit & $\# 9154$ & $1: 1000$ & CST $^{\#}$ \\
Rab34 & Rabbit & ab73383 & $1: 1000$ & Abcam \\
\hline
\end{tabular}




\section{Cellular Physiology Cell Physiol Biochem 2018;47:2360-2368

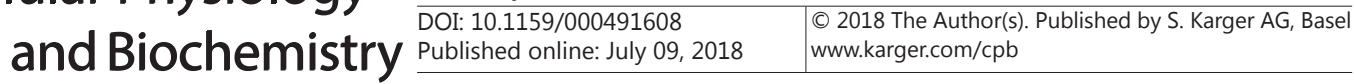 \\ Deng et al.: CSN6 and Rab34 in AR Trafficking}

GST-Raf1-RBD. The spin cup was sealed and kept in $4^{\circ} \mathrm{C}$ for $1 \mathrm{~h}$ with gentle rocking. After three washes reducing sample buffer was added to elute the samples. Samples were heated for $5 \mathrm{~min}$ at $98^{\circ} \mathrm{C}$, cooled, then subjected to SDS-PAGE. Resolved proteins were transferred to a membrane that was incubated with $5 \%$ BSA in TBST buffer for $1 \mathrm{~h}$. The membrane was then incubated with Ras mouse antibody provided in the kit as a 1:200 dilution overnight at $4^{\circ} \mathrm{C}$. After three washes, the membrane was incubated with anti-mouse IgG, horseradish peroxidase-linked antibody (1:2000, \#7076; Cell Signaling Technology) for $1 \mathrm{~h}$ at room temperature. Ras activity was detected using LumiGLO® substrate supplied in the kit.

\section{Statistical analyses}

Data are represented as mean \pm SEM. The statistical significance of the differences between groups was determined by one- or two-way ANOVA followed by Fisher protected least-significant difference post hoc test using software SigmaPlot. Statistical significance was set at $P<0.05$.

\section{Results}

\section{Identification of candidate proteins by MS and bioinformatic analysis}

As described in a previous study, testosterone induces AR translocation to membrane in primary Sertoli cells, with translocation becoming significantly evident within 5 min [14]. To clarify the molecular mechanism of AR translocation to the membrane fraction, we used anti-AR antibody to immunoprecipitate the molecules that associated with AR. The co-IP samples were loadeding for Western blot and silver staining (Fig.1).Western blot analysis routinely showed the expected AR translocation from the cytoplasm to the membrane after exposure to testosterone in input samples. For the co-IP analysis, AR localization in the membrane fraction was increased after testosterone treatment, indicating immunoprecipitation due to anti-AR antibody. Silver staining indicated different expression levels of proteins in the control and testosterone group of the membrane fraction. Further co-IP samples collected using TM4 cells were used for MS analysis.

MS was performed twice and the proteins detected in both procedures were identified as candidate proteins. Thirty-four proteins were identified (Table 2). Bioinformatic analysis including gene ontology (GO) analysis, Kyoto Encyclopedia of Genes and Genomes (KEGG) pathway analysis, and

Table 2. Candidate proteins identified by Mass Spectrometry. OS: Original Species; GN: Gene; PE: Protein Existence; SV: Sequence Version. The columns with grey background and bold font indicates the final nine candidate proteins

\begin{tabular}{|c|c|c|}
\hline No. & Protein & Annotation \\
\hline 1 & VAPA_MOUSE & Vesicle-associated membrane protein-associated protein $A O S=$ Mus musculus $G N=V a p a ~ P E=1 S V=2$ \\
\hline 2 & TUR8_MOUSE & Tumor rejection antigen $\mathrm{P} 815 \mathrm{~A}$ OS=Mus musculus $\mathrm{GN}=\mathrm{Trap} 1 \mathrm{a} \mathrm{PE}=2 \mathrm{SV}=1$ \\
\hline 3 & TPM1_MOUSE & Tropomyosin alpha- 1 chain $0 \mathrm{~S}=$ Mus musculus $\mathrm{GN}=\mathrm{Tpm} 1 \mathrm{PE}=1 \mathrm{SV}=1$ \\
\hline 4 & TNIK_MOUSE & Traf2 and NCK-interacting protein kinase $\mathrm{OS}=$ Mus musculus $\mathrm{GN}=\mathrm{Tnik} \mathrm{PE}=1 \mathrm{SV}=2$ \\
\hline 5 & TITIN_MOUSE & Titin OS=Mus musculus GN=Ttn PE=1 SV=1 \\
\hline 6 & SMC1B_MOUSE & Structural maintenance of chromosomes protein $1 \mathrm{~B}$ OS=Mus musculus $\mathrm{GN}=\mathrm{Smc} 1 \mathrm{~b} \mathrm{PE}=1 \mathrm{SV}=1$ \\
\hline 7 & RL35_MOUSE & $60 \mathrm{~S}$ ribosomal protein $\mathrm{L} 35$ OS=Mus musculus $\mathrm{GN}=\mathrm{Rp} 135 \mathrm{PE}=2 \mathrm{SV}=1$ \\
\hline 8 & RL12_MOUSE & $60 \mathrm{~S}$ ribosomal protein $\mathrm{L} 12 \mathrm{OS}=$ Mus musculus $\mathrm{GN}=\mathrm{Rp} 112 \mathrm{PE}=1 \mathrm{SV}=2$ \\
\hline 9 & RAB34_MOUSE & Ras-related protein Rab-34 OS=Mus musculus GN=Rab34 PE=1 SV=2 \\
\hline 10 & PCLO_MOUSE & Protein piccolo $\mathrm{OS}=$ Mus musculus $\mathrm{GN}=\mathrm{Pclo} \mathrm{PE}=1 \mathrm{SV}=3$ \\
\hline 11 & P5CR2_MOUSE & Pyrroline-5-carboxylate reductase $2 \mathrm{OS}=$ Mus musculus $\mathrm{GN}=\mathrm{Pycr} 2 \mathrm{PE}=2 \mathrm{SV}=1$ \\
\hline 12 & MYL6_MOUSE & Myosin light polypeptide $6 \mathrm{OS}=$ Mus musculus $\mathrm{GN}=\mathrm{Myl} 6 \mathrm{PE}=1 \mathrm{SV}=3$ \\
\hline 13 & MYH9_MOUSE & Myosin- 9 OS=Mus musculus GN=Myh $9 \mathrm{PE}=1 \mathrm{SV}=4$ \\
\hline 14 & MY18A_MOUSE & Myosin-XVIIIa OS=Mus musculus GN=Myo18a PE=1 SV=2 \\
\hline 15 & KRT35_MOUSE & Keratin, type I cuticular Ha $0 \mathrm{OS}=$ Mus musculus GN=Krt35 PE=2 SV=1 \\
\hline 16 & KCD10_MOUSE & BTB/POZ domain-containing protein KCTD10 OS=Mus musculus GN=Kctd10 PE=2 SV=1 \\
\hline 17 & K2C5_MOUSE & Keratin, type II cytoskeletal 5 OS=Mus musculus $\mathrm{GN}=\mathrm{Krt} 5 \mathrm{PE}=1 \mathrm{SV}=1$ \\
\hline 18 & K1C14_MOUSE & Keratin, type I cytoskeletal 14 OS=Mus musculus GN=Krt14 PE=1 SV=2 \\
\hline 19 & K1C10_MOUSE & Keratin, type I cytoskeletal $10 \mathrm{OS}=$ Mus musculus $\mathrm{GN}=\mathrm{Krt10} \mathrm{PE}=1 \mathrm{SV}=3$ \\
\hline 20 & H2B1A_MOUSE & Histone $\mathrm{H} 2 \mathrm{~B}$ type $1-\mathrm{A}$ OS=Mus musculus $\mathrm{GN}=\mathrm{Hist} 1 \mathrm{~h} 2 \mathrm{ba} \mathrm{PE}=2 \mathrm{SV}=3$ \\
\hline 21 & FLNA_MOUSE & Filamin-A OS=Mus musculus $\mathrm{GN}=\mathrm{Flna} \mathrm{PE}=1 \mathrm{SV}=4$ \\
\hline 22 & ERH_MOUSE & Enhancer of rudimentary homolog $\mathrm{OS}=$ Mus musculus $\mathrm{GN}=\mathrm{Erh} P E=1 \mathrm{SV}=1$ \\
\hline 23 & EPHAA_MOUSE & Ephrin type- $\mathrm{A}$ receptor $10 \mathrm{OS}=$ Mus musculus $\mathrm{GN}=\mathrm{Epha} 10 \mathrm{PE}=2 \mathrm{SV}=2$ \\
\hline 24 & EEA1_MOUSE & Early endosome antigen $1 \mathrm{OS}=$ Mus musculus $\mathrm{GN}=$ Eea1 $P E=2 \mathrm{SV}=2$ \\
\hline 25 & CSN6_MOUSE & COP9 signalosome complex subunit 6 OS=Mus musculus $\mathrm{GN}=\mathrm{Cops} 6 \mathrm{PE}=1 \mathrm{SV}=1$ \\
\hline 26 & COPA_MOUSE & Coatomer subunit alpha $\mathrm{OS}=$ Mus musculus $\mathrm{GN}=\mathrm{Copa} \mathrm{PE}=1 \mathrm{SV}=1$ \\
\hline 27 & COF1_MOUSE & Cofilin-1 OS=Mus musculus GN=Cf1 $1 \mathrm{PE}=1 \mathrm{SV}=3$ \\
\hline 28 & C01A1_MOUSE & Collagen alpha- 1 (I) chain $O S=$ Mus musculus $\mathrm{GN}=\mathrm{Col} 1 \mathrm{a} 1 \mathrm{PE}=1 \mathrm{SV}=4$ \\
\hline 29 & CAV1_MOUSE & Caveolin -1 OS=Mus musculus GN=Cav1 PE=2 SV=2 \\
\hline 30 & AXN1_MOUSE & Axin-1 OS=Mus musculus GN=Axin1 PE=1 SV=2 \\
\hline 31 & ARPC3_MOUSE & Actin-related protein $2 / 3$ complex subunit 3 OS=Mus musculus $\mathrm{GN}=\mathrm{Arpc} 3 \mathrm{PE}=1 \mathrm{SV}=3$ \\
\hline 32 & AR_MOUSE & Androgen Receptor OS=Mus musculus GN=Ar PE=3 SV=3 \\
\hline 33 & ACTB_MOUSE & Actin, cytoplasmic 1 OS=Mus musculus $\mathrm{GN}=\mathrm{Actb} P E=1 \mathrm{SV}=1$ \\
\hline 34 & ABLM1_MOUSE & Actin-binding LIM protein 1 OS=Mus musculus GN=Ablim $1 \mathrm{PE}=1 \mathrm{SV}=1$ \\
\hline
\end{tabular}


STRING Protein-Protein Interaction Networks analysis were used for further screening. Finally, nine candidate proteins (grey background and bold font in Table 2) were selected for further verification.

\section{CSN6 is involved in AR trafficking}

CSN6 (COP9 signalosome complex subunit 6) is one subunit of the constitutive photomorphogenesis 9 (COP9) signalosome (CSN), which is an evolutionarily conserved multi-protein complex found in plants and animals. Western blot showed an increase expression of AR and CSN6 in the membrane fraction after exposure to testosterone, and a slight decrease in the cytoplasmic fraction. Aliquots of cytoplasmic and membrane protein were subjected to co-IP using anti-AR antibody. Western blot analysis using the co-IP samples revealed an increased association of CSN6 with AR in the membrane fraction and a decreased association in the cytoplasmic fraction (Fig. 2A). These data verified the MS analysis and suggested that CSN6 plays a critical role in AR trafficking.

TM4 cells were transfected with shRNA or negative control. Representative Western blot data showed a significantly decrease in the expression of CSN6 by shRNA (Fig. 2B, $P$ $<0.01)$. CSN6 knockdown by shRNA significantly decreased the localization of AR to the membrane $(P<0.05)$ and nuclear $(P<0.05)$ fraction in the basal condition, and significantly prevented AR translocation to membrane $(P<0.01)$ and nuclear $(P<0.01)$ after exposure to testosterone (Fig. 2C).

\section{CSN6 knockdown down-regulate phosphorylation signaling pathway}

CSN6 reportedly controls the proliferation and metastasis of glioblastoma by chromatin immunoprecipitation-mediated degradation of epidermal growth factor receptor (EGFR) [15], extracellular regulated protein kinases (Erk)1/2-dependent phosphorylation of CSN6 is critical in colorectal cancer development [16]. We examined whether CSN6 is involved in

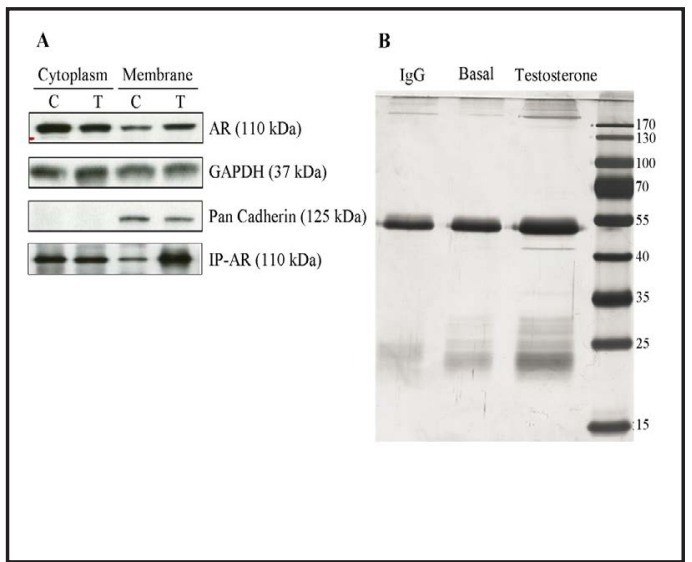

Fig. 1. Identification of candidate proteins by silver staining. A, Representative Western blots using primary cultured Sertoli cells show the cytoplasmic and membrane AR translocation in input samples and co-IP samples. This experiment was repeated three times. B, A representative silver stained gel using primary cultured Sertoli cells showing the coIP samples of the membrane proteins. This staining was repeated twice using TM4 cells by the Fitgene Biotechnology Co. Ltd.

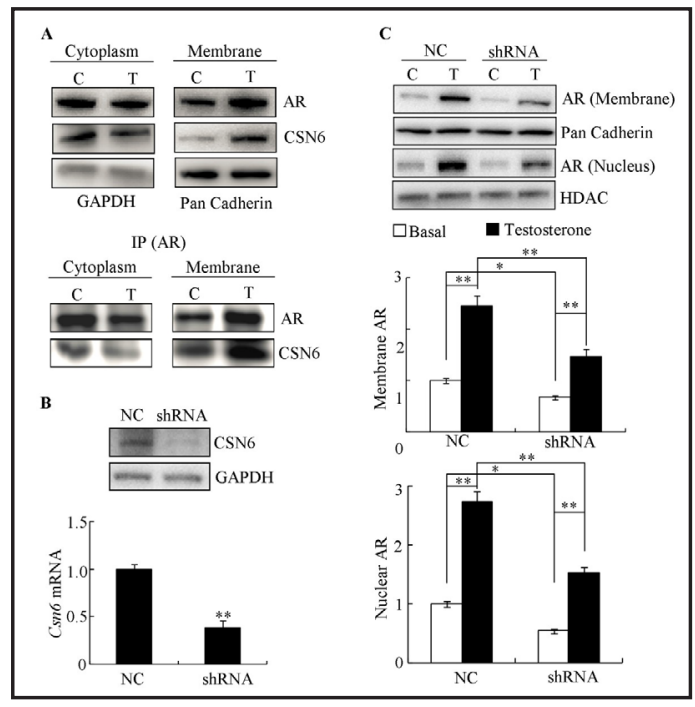

Fig. 2. CSN6 is involved in $A R$ trafficking in TM4 cells. A, MS data was verified by Western blot analysis. B, CSN6 was knocked down by shRNA. The experiments were done three times. C, Representative Western blot and statistical analysis data revealed a decreased membrane and nuclear AR localization in the basal condition in the CSN6 shRNA group, as well as the inhibition of AR membrane and nuclear translocation after exposure to testosterone $(\mathrm{n}=3)$. ${ }^{*}, \mathrm{P}<0.05,{ }^{* *}, \mathrm{P}<0.01$. 


\section{Cellular Physiology Cell Physiol Biochem 2018;47:2360-2368 \begin{tabular}{l|l} 
DOI: 10.1159/000491608 & $\begin{array}{l}\text { O 2018 The Author(s). Published by S. Karger AG, Basel } \\
\text { www.karger.com/cpb }\end{array}$
\end{tabular} \\ Deng et al.: CSN6 and Rab34 in AR Trafficking}

Fig. 3. CSN6 knockdown down-regulates the phosphorylation signaling pathway in TM4 cells. A, Cells were stimulated by $10 \mathrm{nM}$ testosterone for 5 min. Representative Western blot analysis revealed decreased phosphorylation levels corresponding to the kinase phosphorylation site in cells transfected with CNS6 shRNA. B-D, Data analysis of the repeated experiments $(n=3)$. NC, Negative control, cells were transfected with a control shRNA. *, $\mathrm{P}<0.05$, **, $\mathrm{P}<0.01$.

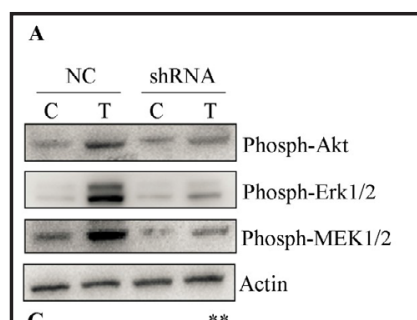

C
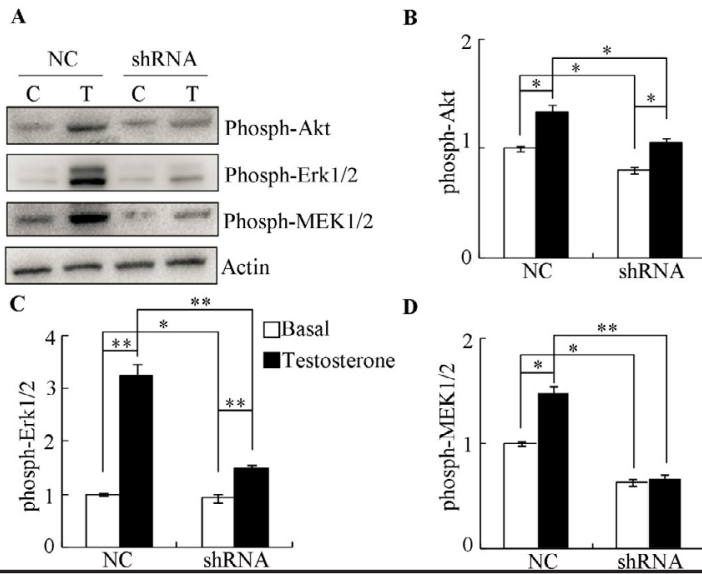

D

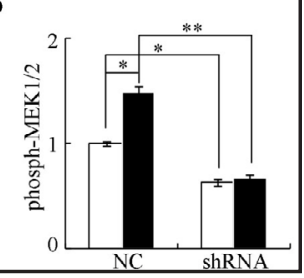

Fig. 4. Rab34 is involved in AR trafficking in TM4 cells. A, MS data were verified by Western blot analysis. B, Rab34 was knocked down by Rab34 shRNA ( $\mathrm{n}=3$ ). C, Representative Western blot data revealed decreased membrane and nuclear AR localization in the basal condition in the Rab34 shRNA group and inhibition of AR membrane and nuclear translocation after exposure to testosterone. D, Statistical analysis of the collected data from repeated experiments $(n=3)$. NC: Negative control, cells was transfected with a control shRNA. *, $\mathrm{P}<0.05$, **, $\mathrm{P}<0.01$.

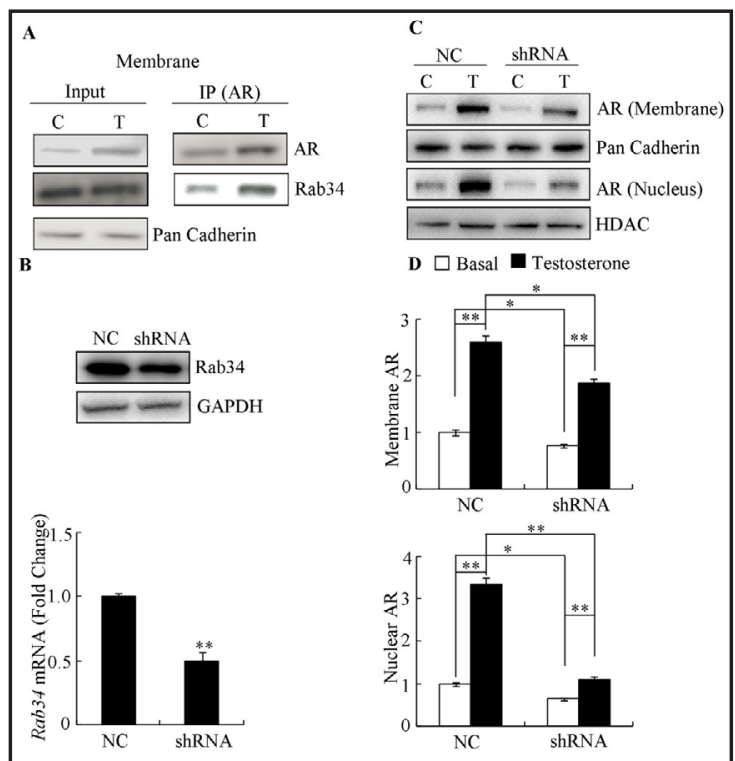

the protein phosphorylation signaling pathway that mediates the non-classical pathway of androgen. Consistent with the previous studies [6,14,17], Western blot analysis using TM4 cells revealed the rapid increase in the phosphorylation of kinase protein kinase B (Akt) (Ser473), Erk1/2 (Thr202/Tyr204), and mitogen activated protein kinase kinase (MEK1/2) (Ser217/221) within 5 min. Knockdown of CSN6 by shRNA inhibited the increase in the phosphorylation caused by testosterone stimulation (Fig. 3).

\section{Rab34 is involved in AR trafficking}

Rab34 belongs to the RAB family of proteins, which are small GTPases involved in protein transport. Rab34 is reportedly localized to the membranes [18]. Western blot using co-IP samples from the membrane protein fraction by the anti-AR antibody revealed an increased association of Rab34 with AR after exposure to testosterone (Fig. 4A). Knockdown of Rab34 by shRNA significantly inhibited AR localization to the membrane $(P<0.05)$, nuclear fraction $(P<0.05)$, AR membrane $(P<0.05)$, and nuclear trafficking $(P<0.01)$ after exposure to testosterone (Fig. 4C \& 4D).

Ras activity is decreased in cells transfected with Rab34 shRNA

Rab34 is a Ras related protein that is involved in cellular vesicle transport [19]. Western blotting revealed decreased Ras activity in cells transfected with Rab34 shRNA, compared 


\section{Cellular Physiology Cell Physiol Biochem 2018;47:2360-2368 \begin{tabular}{ll|l} 
DOI: 10.1159/000491608 & O 2018 The Author(s). Published by S. Karger AG, Basel \\
www.karger.com/cpb
\end{tabular} \\ Deng et al.: CSN6 and Rab34 in AR Trafficking}

with the cell with negative control (Fig. 5A). This was verified by repeated experiments (Fig. 5B).

\section{Discussion}

Spermatogenesis is a complex and highly ordered process that is regulated by a series of gene products. Many clinical and experimental studies have suggested that androgen and its receptor are critical for spermatogenesis and male fertility. Androgen controls spermatogenesis mainly by associated with the AR localized in Sertoli cells, and the role of androgen in Sertoli cells includes maintaining blood-testis barrier, meiosis, Sertoli-spermatid adhesion, and sperm release.

AR is capable of transmitting testosterone signals by at least two mechanisms, the classical and non-classical pathways. In the

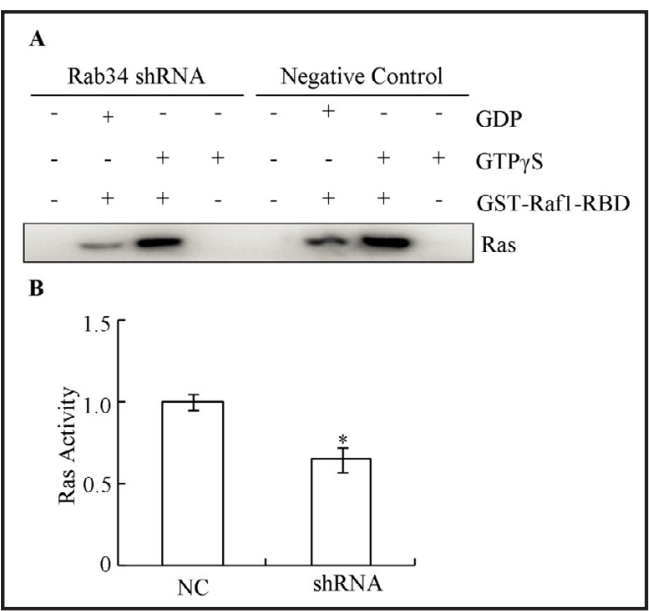

Fig. 5. Ras activity is decreased in TM4 cells transfected with Rab34 shRNA. A, Ras activity was determined as described in Materials and methods. B, Data from repeated experiments $(\mathrm{n}=3) . *$, $\mathrm{P}<0.05$. classical signaling pathway, testosterone that diffuses through the cell membrane interacts with AR in the cytoplasm, and then translocates to nucleus, binds AREs in gene regulatory regions and recruits co-activator or co-repressor proteins to regulate gene expression [20].

In the non-classical pathway, stimulation of Sertoli cells with levels of testosterone (10$250 \mathrm{nM}$ ) that are similar to or lower than that found in the testis causes a population of AR to localize near the plasma membrane. Western blot and immunofluorescence examinations have previously confirmed the localization of AR to the plasma membrane [21]. Binding of testosterone to the AR allows the receptor to interact with and activate Src tyrosine kinase. Once activated, Src causes the phosphorylation of EGFR via an intracellular pathway, as well as kinase Ras. The stimulation of EGFR results in the activation of the mitogen-activated protein kinase cascade including the kinases RAF, MEK and Erk [20]. Presently testosterone induced the membrane localization of AR within 5 min.

To clarify the molecular mechanism of AR trafficking to the membrane, we identified the candidate proteins involved in this action using MS and bioinformatic analysis. Nine candidate proteins were identified and confirmed, and the molecular mechanism mediating AR trafficking by these proteins were studied.

Our data show that the binding of CSN6 to AR was decreased in the cytoplasm, and increased at the membrane after exposure to testosterone. The knockdown of CSN6 prevented AR membrane and nuclear localization, as well as AR trafficking. These data indicated that CSN6 is involved in AR intracellular trafficking. Moreover, it was previously reported that CSN6 interacts with Erk, to down regulate the EGFR signaling pathway [15]. The activation of this pathway is critical for the release of the sperm from Sertoli cells, and for blood-testis barrier integrity [20]. Rapid increases in kinase Akt (Ser473), Erk1/2 (Thr202/Tyr204), and MEK1/2 (Ser217/221) were induced by testosterone within 5 min, and knockdown of CSN6 prevented the stimulation. Our previous studies showed that inhibition of the kinase (Akt, Erk and MEK) by inhibitors block AR trafficking caused by testosterone administration [14]. These data suggested that CSN6 regulates AR trafficking via the phosphorylation signaling pathway. The precise molecular mechanism of AR trafficking in Sertoli cells mediated by phosphorylation signaling pathway is still unclear.

Rab protein almost completely localizes in the membrane associated organelles of eukaryotic cells. The protein has critical roles in maintaining continuous protein transport and integrity of organelle membrane [22]. As a member of Rab family, Rab34 is involved in the 


\section{Cellular Physiology Cell Physiol Biochem 2018;47:2360-2368 \begin{tabular}{l|l} 
DOI: 10.1159/000491608 & $\begin{array}{l}\text { O 2018 The Author(s). Published by S. Karger AG, Basel } \\
\text { www.karger.com/cpb }\end{array}$
\end{tabular} \\ Deng et al.: CSN6 and Rab34 in AR Trafficking}

repositioning of lysosomes and the activation of macropinocytosis; this feature is common to the family members [23]. A knockout and rescue experiment verified Rab34 mediated protein transport to the plasma membrane [19]. It was reported that the association of Rab34 with Rab interacting lysosomal protein initiates the movement of the protein microtubule [24]. Membrane Rab34 promote the binding of the protein to the plasma membrane, and the trafficking of lysosomes to microtubule [25]. Rab34 exerts its biological action by regulating protein kinase D and phosphatidylinositol 4-phosphate [26, 27]. Our data indicated that Rab34 is involved in AR localization, and AR trafficking, through regulation of the activity of Ras.

\section{Conclusion}

We identified CSN6 and Rab34 as key proteins involved in AR trafficking in mouse testicular cells. CSN6 and Rab34 control AR transport mainly via the regulation of the phosphorylation signaling pathways. The detailed molecular mechanism still needs further research. Further studies will be conducted to explore the effect of this phosphorylation signaling pathway in maintaining spermatogenesis and male fertility.

\section{Acknowledgements}

The author(s) disclosed receipt of the following financial support for the research, authorship, and/or publication of this article: This work was supported by Grants from Guangdong Natural Science Foundation (2016A030310071), Shenzhen Science and Technology Planning Project (JCYJ20160428171238706, JCYJ20170307141840188), and Shenzhen Health and Family Planning Commission Project (201605017), and Program of Technology and Innovation of Longhua, Shenzhen (20150925A0410013).

\section{Disclosure Statement}

The authors declare to have no potential conflict of interests in respect to the research, authorship, and/or publication of this article.

\section{References}

-1 Chang C, Chen YT, Yeh SD, Xu Q Wang RS, Guillou F, Lardy H, Yeh S: Infertility with defective spermatogenesis and hypotestosteronemia in male mice lacking the androgen receptor in Sertoli cells. Proc Natl Acad Sci U S A 2004;101:6876-6881.

$\longrightarrow 2$ De Gendt K, Swinnen JV, Saunders PT, Schoonjans L, Dewerchin M, Devos A, Tan K, Atanassova N, Claessens F, Lecureuil C, Heyns W, Carmeliet P, Guillou F, Sharpe RM, Verhoeven G: A Sertoli cell-selective knockout of the androgen receptor causes spermatogenic arrest in meiosis. Proc Natl Acad Sci U S A 2004;101:13271332.

-3 Wang RS, Yeh S, Chen LM, Lin HY, Zhang C, Ni J, Wu CC, di Sant'Agnese PA, deMesy-Bentley KL, Tzeng $\mathrm{CR}$, Chang C: Androgen receptor in sertoli cell is essential for germ cell nursery and junctional complex formation in mouse testes. Endocrinology 2006;147:5624-5633.

4 Tsai MY, Yeh SD, Wang RS, Yeh S, Zhang C, Lin HY, Tzeng CR, Chang C: Differential effects of spermatogenesis and fertility in mice lacking androgen receptor in individual testis cells. Proc Natl Acad Sci U S A 2006;103:18975-18980.

5 Shang Y, Myers M, Brown M: Formation of the androgen receptor transcription complex. Mol Cell 2002;9:601-610. 


\section{Cellular Physiology Cell Physiol Biochem 2018;47:2360-2368 \begin{tabular}{l|l|l} 
DOI: 10.1159/000491608 & O 2018 The Author(s). Published by S. Karger AG, Basel \\
www.karger.com/cpb
\end{tabular} \\ Deng et al.: CSN6 and Rab34 in AR Trafficking}

6 Fix C, Jordan C, Cano P, Walker WH: Testosterone activates mitogen-activated protein kinase and the cAMP response element binding protein transcription factor in Sertoli cells. Proc Natl Acad Sci U S A 2004;101:10919-10924.

7 Hua SY, Chen YZ: Membrane receptor-mediated electrophysiological effects of glucocorticoid on mammalian neurons. Endocrinology 1989;124:687-691.

-8 Pedram A, Razandi M, Sainson RC, Kim JK, Hughes CC, Levin ER: A conserved mechanism for steroid receptor translocation to the plasma membrane. J Biol Chem 2007;282:22278-22288.

\$ El-Hefnawy T, Manna PR, Luconi M, Baldi E, Slotte JP, Huhtaniemi I: Progesterone action in a murine Leydig tumor cell line (mLTC-1), possibly through a nonclassical receptor type. Endocrinology 2000;141:247-255.

$>10$ Peluso JJ, Fernandez G, Pappalardo A, White BA: Characterization of a putative membrane receptor for progesterone in rat granulosa cells. Biol Reprod 2001;65:94-101.

11 Deng Q, Wu Y, Zhang Z, Wang Y, Li M, Liang H, Gui Y: Androgen Receptor Localizes to Plasma Membrane by Binding to Caveolin-1 in Mouse Sertoli Cells. Int J Endocrinol 2017;2017:3985916.

12 Chang H, Gao F, Guillou F, Taketo MM, Huff V, Behringer RR: Wt1 negatively regulates beta-catenin signaling during testis development. Development 2008;135:1875-1885.

13 Deng Q Riquelme D, Trinh L, Low MJ, Tomic M, Stojilkovic S, Aguilera G: Rapid Glucocorticoid Feedback Inhibition of ACTH Secretion Involves Ligand-Dependent Membrane Association of Glucocorticoid Receptors. Endocrinology 2015;156:3215-3227.

14 Deng Q Zhang Z, Wu Y, Yu WY, Zhang J, Jiang ZM, Zhang Y, Liang H, Gui YT: Non-Genomic Action of Androgens is Mediated by Rapid Phosphorylation and Regulation of Androgen Receptor Trafficking. Cell Physiol Biochem 2017;43:223-236.

15 Hou J, Deng Q, Zhou J, Zou J, Zhang Y, Tan P, Zhang W, Cui H: CSN6 controls the proliferation and metastasis of glioblastoma by CHIP-mediated degradation of EGFR. Oncogene 2017;36:1134-1144.

-16 Fang L, Lu W, Choi HH, Yeung SC, Tung JY, Hsiao CD, Fuentes-Mattei E, Menter D, Chen C, Wang L, Wang J, Lee MH: ERK2-Dependent Phosphorylation of CSN6 Is Critical in Colorectal Cancer Development. Cancer Cell 2015;28:183-197.

17 Cheng J, Watkins SC, Walker WH: Testosterone activates mitogen-activated protein kinase via Src kinase and the epidermal growth factor receptor in sertoli cells. Endocrinology 2007;148:2066-2074.

18 Takai Y, Sasaki T, Matozaki T: Small GTP-binding proteins. Physiol Rev 2001;81:153-208.

19 Goldenberg NM, Grinstein S, Silverman M: Golgi-bound Rab34 is a novel member of the secretory pathway. Mol Biol Cell 2007;18:4762-4771.

20 Smith LB, Walker WH: The regulation of spermatogenesis by androgens. Semin Cell Dev Biol 2014;30:2-13.

21 Walker WH: Non-classical actions of testosterone and spermatogenesis. Philos Trans R Soc Lond B Biol Sci 2010;365:1557-1569.

22 Militello R, Colombo MI: Small GTPases as regulators of cell division. Commun Integr Biol 2013;6:e25460.

23 Wang T, Hong W: Assay and functional properties of Rab34 interaction with RILP in lysosome morphogenesis. Methods Enzymol 2005;403:675-687.

-24 Wang T, Hong W: Interorganellar regulation of lysosome positioning by the Golgi apparatus through Rab34 interaction with Rab-interacting lysosomal protein. Mol Biol Cell 2002;13:4317-4332.

-25 Sun P, Yamamoto H, Suetsugu S, Miki H, Takenawa T, Endo T: Small GTPase Rah/Rab34 is associated with membrane ruffles and macropinosomes and promotes macropinosome formation. J Biol Chem 2003;278:4063-4071.

-26 Liljedahl M, Maeda Y, Colanzi A, Ayala I, Van Lint J, Malhotra V: Protein kinase D regulates the fission of cell surface destined transport carriers from the trans-Golgi network. Cell 2001;104:409-420.

27 Hausser A, Storz P, Martens S, Link G, Toker A, Pfizenmaier K: Protein kinase D regulates vesicular transport by phosphorylating and activating phosphatidylinositol-4 kinase IIIbeta at the Golgi complex. Nat Cell Biol 2005;7:880-886. 